УДК $398+82$ I.I6I.I.O

ББК $82.3+83.3(2 \mathrm{Poc}=\mathrm{Pyc}) 6$
НОВЫЕ ПОСТУПЛЕНИЯ В ФОНДЫ МОСКОВСКОГО ЛИТЕРАТУРНОГО МУЗЕЯ-ЦЕНТРА К.Г. ПАУСТОВСКОГО

(C) 2018 г. А.И. Дормидонтова Московский литературный музей-центтр К.Г. Паустовского, Москва, Россия Дата поступления статьи: І2 января 2018 г. Дата публикащии: 25 марта 2018 г.

DOI: I0.22455/2500-4247-20I8-3-I-332-343

Аннотация: Представлен обзор новых материалов, поступивших в Московский литературный музей-центр К.Г. Паустовского в 2017 г., в год І25-летия со дня рождения писателя. Коллекция состоит из 366 единиц хранения. Это рукописи творческого характера, биографические документы, письма, книги с автографами, а также фотографии, афиши, буклеты, рисунки. Они представляют значительный интерес для изучения творческой лаборатории писателя, его биографии, для уяснения круга его общения и контактов с современниками. В обзоре воспроизводится ряд документов.

Ключевые слова: К.Г. Паустовский, рукописи, биография, творческая история произведений, переписка, дарственные надписи, Московский литературный музей-центр К.Г. Паустовского.

Информация об авторе: Анжелика Игоревна Дормидонтова - кандидат культурологии, директор Московского литературного музея-центра К.Г. Паустовского, ул. Кузьминская, д. 8, Іо9472 г. Москва, Россия.

E-mail: angelica_d@mail.ru 


\section{NEW ADMISSIONS TO THE K.G. PAUSTOVSKY MOSCOW LITERARY MUSEUM-CENTER}

This is an open access article distributed under the Creative Commons Attribution 4.0 International (CC BY 4.0)
(C) 20I8. A.I. Dormidontova

K.G. Paustovsky Moscow Literary Museum-Center, Moscow, Russia

Received: January $\mathrm{I} 2,2018$

Date of publication: March 25, 2018

Abstract: This is an overview of a new collection received by the K.G. Paustovsky Moscow Literary Museum-Center in 20I7, the year of the I25th anniversary of his birth. The collection consists of 366 items. Among them are manuscripts, biographical documents, letters, books with autographs, photographs, posters, booklets, and drawings. These items are of considerable interest for the study of the writer's methods, his biography as well as for understanding the circle of his contacts. The overview incorporates a number of authentic documents.

Keywords: Konstantin Paustovsky, manuscripts, biography, history of literary works, correspondence, inscriptions, K.G. Paustovsky Moscow Literary Museum-Center.

Information about the author: Angelica I. Dormidontova, $\mathrm{PhD}$ in Cultural Studies, Director of the K.G. Paustovsky Moscow Literary Museum-Center, Kuzminskaya 8, I09472 Moscow, Russia.

E-mail: angelica_d@mail.ru 
В 2017 г. в России широко отмечалось І25-летие со дня рождения К.Г. Паустовского. Прошли международные научно-практические конференции, были организованы выставки, круглые столы, конкурсы, реализованы различные образовательные проекты, вышли книги писателя, наблюдался значительный рост числа научных публикаций о нем, а также материалов в печатных и электронных СМИ. Среди наиболее важных событий прошедшего года - значительное пополнение фондов Московского литературного музея-центра К.Г. Паустовского. Правительством Москвы была закуплена коллекция рукописей, писем, книг с автографами, а также других уникальных документов. Коллекция включает в себя 366 мемориальных предметов.

Среди приобретенных документов особую ценность имеет открытка, отправленная К.Г. Паустовскому И.А. Буниным I5 сентября 1947 г.

В открытке содержится отзыв на рассказ К.Г. Паустовского «Корчма на Брагинке», являющийся главой автобиографической книги писателя «Повесть о жизни»:

Дорогой Собрат! Я прочел Ваш рассказ «Корчма на Брагинке» и хочу Вам сказать о той редкой радости, которую испытал я: если исключить последнюю фразу этого рассказа («Под занавес»), он принадлежит к наилучшим рассказам русской литературы.

Привет, всего доброго!

I5.IX.47

Ив. Бунин 

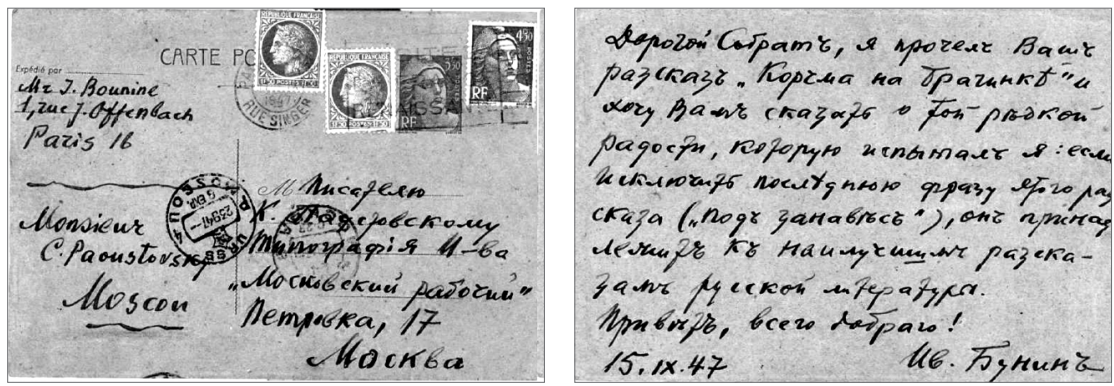

Отзыв И. А. Бунина на рассказ К.Г. Паустовского «Корчма на Брагинке» Ivan Bunin's review of Paustovsky's story "A Tavern at Braginka”

Известно, что К.Г. Паустовский очень дорожил данной открыткой, считал ее своей самой большой литературной наградой. Поступление этого документа в фонды музея, в котором хранится значительная часть писательского архива, - символический подарок писателю в юбилейный год.

В коллекцию также входят книги с автографами К.Г. Паустовского, фотографии, письма, записки, афиши, буклеты, рисунки, различные документы. Они относятся к периоду 1930-І940-х гг. и имеют высокую ценность для коллекции музея, так как данный период жизни и творчества К.Г. Паустовского ранее был представлен в музейном собрании малым числом материалов.

Особо ценными среди документов, пополнивших музейные фонды, являются рукописи (рабочие записи) пьес К.Г. Паустовского «Созвездие гончих псов», «Пока не остановится сердце», «Наш современник»; письма и телеграммы периода Великой Отечественной войны (I94I-I945); личные документы, фотографии и удостоверения писателя I9I7-I94I гг.

Книги с автографами К.Г. Паустовского хранились наследниками второй жены писателя Валерии Владимировны Валишевской на протяжении 60 лет. Автографы писателя представлены на прижизненных изданиях его произведений: «Мещёрская сторона», «Дождливый рассвет», «Кара-Бугаз», «Степная гроза», «Монисто». В коллекции также имеются автографы на изданиях произведений писателя на иностранных языках и книгах других авторов (Шарль де Костер «Легенда об Уленспигеле и Ламме Гудзаке», И. Гончаров «Обрыв», Р. Джованьолли «Спартак»). На авантитулах и форзацах некоторых книг приклеена марка «А.С. Пушкин» (юбилейная). Известно, что К.Г. Паустовский в І930-I940-е гг. помечал данной маркой книги из лич- 
ной библиотеки, так как не имел собственного экслибриса. Книжные здания с такой же маркой хранятся в Мемориальном доме писателя в Тарусе. Автографы на книгах поступившей в музей-центр коллекции обращены к В.В. Валишевской и приемному сыну писателя Сергею Михайловичу Навашину. Записи носят личный характер, указывают на теплые семейные отношения, свидетельствуют об увлечениях писателя, о географии его поездок и путешествий, о творческих планах, об истории создания некоторых произведений.

Частью данной коллекции является семейный фотоархив 1930I940-х гг. В нем представлены фотографии периода проживания писателя в поселке Солотча Рязанской области; фотографии, сделанные во время поездок писателя в Крым; групповые семейные фотографии. Большой блок фотоархива представлен авторскими фотографиями, сделанными писателем в 1930-I940-е гг. во время путешествий по России. Фотография - одно из любимых увлечений К.Г. Паустовского, однако большая часть сделанных им снимков не сохранилась. Писатель любил фотографировать пейзажи, людей и жанровые сцены из провинциальной жизни. Представленные работы отражают особое «живописное» видение мира писателем, произведения которого часто называют «картинами в прозе».

В данный архив входят также личные документы и записки писателя, относящиеся к периоду I917-1950-х гг. Среди них: удостоверение военного корреспондента TACC (I94I); удостоверение члена Совета работников Сухума (I922); членский билет Всероссийского союза работников просвещения (Московский губотдел; І9I7); членский билет К.Г. Паустовского № 2046I25 (АВИАХИМ РСФСР; 2 июня І926) и другие документы.

Несомненную мемориальную ценность имеет блок писем, телеграмм и записок писателя домочадцам, друзьям, знакомым; а также писем, обращенных к писателю, творческих рукописей К.Г. Паустовского (95 единиц хранения, все документы подлинные). Среди данных документов имеются особо ценные. Это фрагменты рукописей таких произведений, как «Созвездие гончих псов», «Пока не остановится сердце», «Наш современник». Значительный интерес представляют письма и телеграммы военного периода (I94I-I945): телеграмма о возвращении с фронта (I94I), письмо бойца К.Г. Паустовскому с благодарностью за творчество (I942), несколько писем из Алма-Аты, где писатель с семьей находились в период эвакуации. В эту часть коллекции входят письма от редакций разных периодических изданий 
с приглашением к сотрудничеству, приглашение от имени А.А. Фадеева принять участие в работе Шевченковского пленума правления Союза писателей СССР, письмо о защите усадьбы И. Пожалостина в Солотче. Все они имеют несомненную мемориальную, культурную и историческую ценность.

В коллекцию входят также афиши театральных постановок по произведениям К.Г. Паустовского. Работа для театра по созданию сценариев, либретто - малоизученная сторона творчества К.Г. Паустовского. Начиная с І930-х гг. по совету Ю.К. Олеши К.Г. Паустовский начинает писать для театра. Наиболее известны такие его пьесы, как «Простые сердца», «Созвездие гончих псов», «Пока не остановится сердце», «Кружевница Настя», «Преодоление времени», «Поручик Лермонтов», «Наш современник».

Несомненную мемориальную ценность имеют также коллекции писем и книг с автографами К.Г. Паустовского первой жене Екатерине Степановне Загорской и старшему сыну Вадиму Константиновичу Паустовскому.

В фондах музея-центра хранится значительная часть архива первой семьи писателя, переданная на государственное хранение старшим сыном писателя В.К. Паустовским. Из-за сложных жизненных обстоятельств и частых переездов В.К. Паустовского часть семейного архива была им утеряна, в том числе закупленные в настоящее время письма. Приобретение их в коллекцию музея-центра имеет большое значение для изучения творчества и биографии писателя.

В письмах речь идет о частной жизни К.Г. Паустовского, в некоторых из них имеются указания на важные моменты, связанные с его творческой работы над текстами. Например, в письме от 3 января г930 г. содержатся сведения о написании рассказа «Сумрак». Это первое известное нам упоминание об этом произведении.

Книги с автографами К.Г. Паустовского, адресованными сыну В.К. Паустовскому и жене Е.С. Паустовской (Загорской), позволяют восстановить некоторые события жизни писателя и его семьи, доказывают сохранение его теплых отношений со старшим сыном на протяжении всей жизни.

Закупленные предметы имеют исключительную мемориальную и культурно-историческую ценность, требуют всестороннего изучения. Документы были впервые представлены на юбилейных выставочных проектах: мобильной выставке «Россия глазами Паустовского» (Москва, Старый Арбат, I-2I ноября 20I7), на выставках «Паустовский и кино» (Москва, галерея 
«Беляево», І ноября - I5 декабря 20I7) и «Константин Паустовский. Без купюр» (Москва, Государственный музей А.С. Пушкина, выставочные залы на Арбате; г4 декабря 20I7 - 4 февраля 2оІ7 года).

Ниже впервые публикуется несколько документов из поступившей в фонды Московского литературного музея-центра К.Г. Паустовского коллекции.

\section{І. Письмо. К.Г. Паустовского В.К. Паустовскому. 09.08.1937. I л.}

В конверте, с указанием отправителя:

Солотча, Мос<кковской > области, Рязанского района, дом 8о, К.Г. Паустовский

Получатель:

Одоев, Московской области

с. Николо-Жупань

Дом отдыха Литфонда

Вадиму Константиновичу Паустовскому

Москва 9 августа

Димушка-мальчик, получил ли ты мою открытку с реки Десны. Союз писателей послал меня на Десну с двенадцатью московскими комсомольцами, чтобы пройти на лодках от Брянска до Новгород-Северска (около 400 километров). Мы прошли 200 километров до города Трубачевска за 8 дней и там я прекратил эту экспедицию и отправил всех в Москву, т. к. большинство комсомольцев - горожане, совершенно неприспособленные к экспедиционной жизни и не умеющие работать, даже гресть. Был даже один, который впервые в жизни видел, как кипит ключом в котелке вода (на костре) и страшно испугался, - поднял крик на весь лагерь.

Река очень быстрая, в некоторых местах течение идет со скоростью І2 километров в час, есть громадные водовороты и плыть по такой реке с неопытными людьми - очень трудно. Я очень устал, но окреп и страшно загорел. На днях поеду в Солотчу и засяду там за работу на всю осень, - летом я много ездил и работать не успевал. Напиши мне в Солотчу (Солотча, Московской области, Рязанского района, дом 80) как твое здоровье, как ты живешь и когда вернешься в Москву, - я к этому времени пришлю в Москву деньги.

Целую тебя крепко 
Письмо. К.Г. Паустовского В.К. Паустовскому. 09.08.1937

A letter from K.G. Paustovsky to V.K. Paustovsky. 09.08.1937

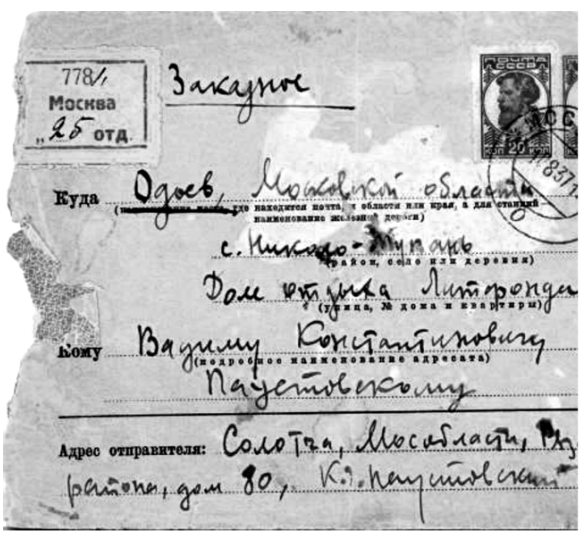

\section{leockba 9 abrucia}

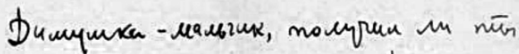
soro otkpbiniky c peren becren. Cores rucaiterent rocuar sums wa becry $c$ gbesragyañitro uoculobckerem komcouseryam, ztío de upointu na logkak ot Splnurea yo thesopoq-Cebepma (Oxoces too kunsvermfoe). Me mpousm 200 keres;

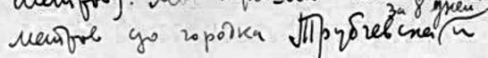

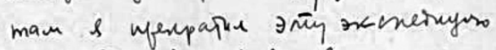
$n$ appabur bes b luscly, $m . K$.

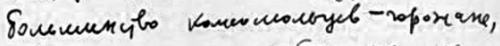

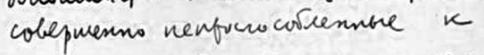

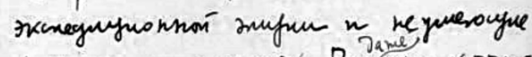

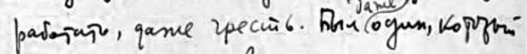

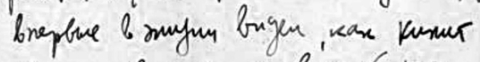
kisorem l koience boga ( her vacrol $x$ croamsno uariparas, -

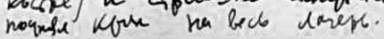

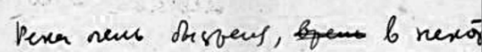
resat trenice nget do cregrsor 12 kicousofe Plac, ent youcasic

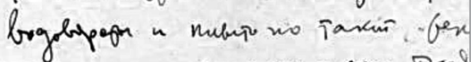

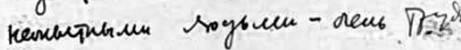
S reces yciar, two oxfen "s croen zenfen. Ha quex noety \& Covoing grution tam ja pasory ha bse ocent, - repour \& uscors gore. parotame ve Ycrelan. Hanumus une b Couoring (Covo

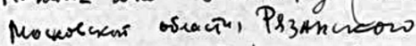
pañonea, gom 80) kan fove Yopobe, cox in mubeuss n visou bepreasus b lessely,

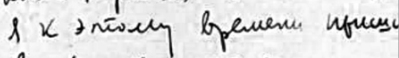
l nocrey genom.

Mana. 


\section{2. Пропуск К.Г. Паустовскому на Красную площадь в день похо- рон А.М. Горького. 20 июня 1936}

Пролетарии всех стран, соединяйтесь! Пропуск № 918

Тов. Паустовский для входа на Красную площадь в день похорон

Алексея Максимовича Горького

20 Июня 1936 года.

\section{Нач. Оперода ГУГБ НКВД}

Комиссар Гос <ударственной $>$ Безопасн< <ости $>2$ ранга Паукер.

Левая трибуна

Вход со стороны площ. Революции через Кремлевский проезд.

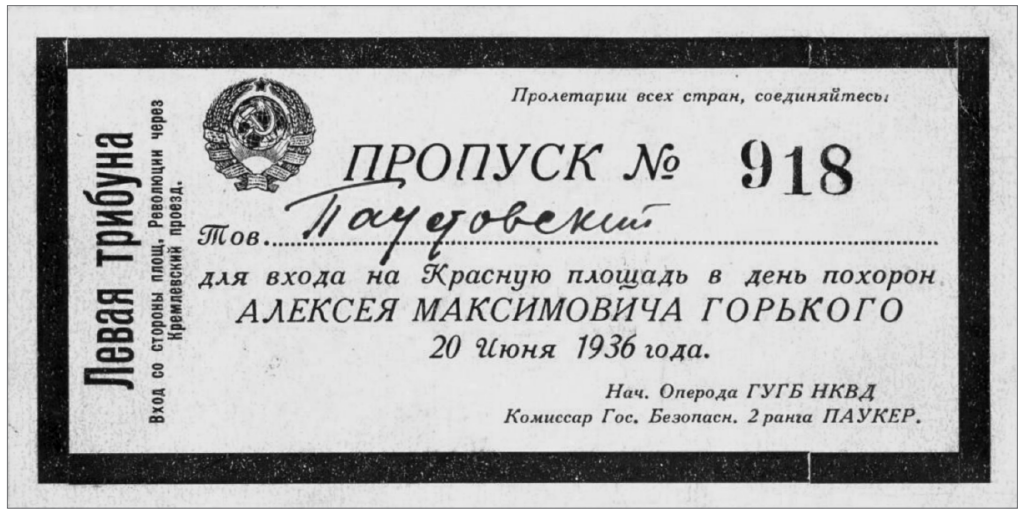

Пропуск К.Г. Паустовскому на Красную площадь в день похорон А.М. Горького. 20 июня 1936

Paustovsky's pass on Red Square on the day of Maxim Gorky's funeral, June 20, I936 


\section{3. Членский билет Всероссийского союза работников просве- щения на имя К.Г. Паустовского}

Пролетарии всех стран, соединяйтесь! ВСЕРОССИЙСКИЙ СОЮЗ РАБОТНИКОВ ПРОСВЕЩЕНИЯ

Московский Губотдел

Членский билет № 5 IIO8

Москва

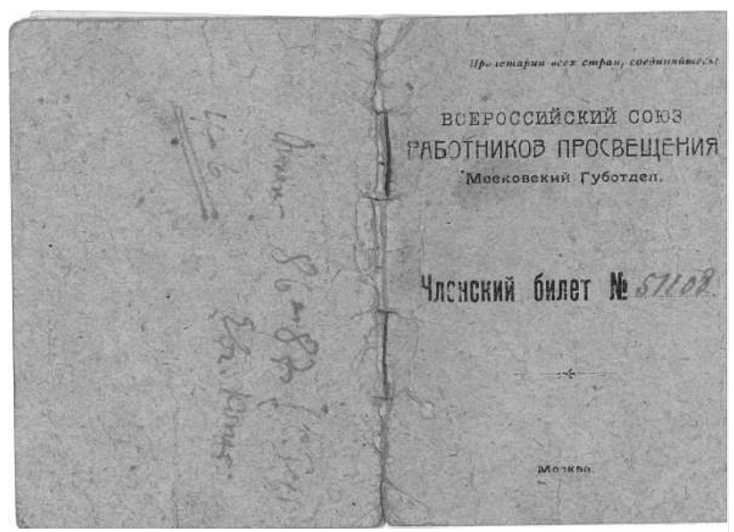

Пролетарии всех стран, соединяйтесь!

Всероссийский Союз Работников Просвещения

Московский Губотдел

Уотделение

Секция Раб<отников > печати

ЧЛЕНСКИЙ БИЛЕТ № 51108

Фамилия Паустовский

Имя, Отчество Конст <антин> Геор <гиевич>

Год рождения 1892

Специальность журнал<ист>-литер <атор >

Семейное положение женат

Число лиц, находящ<ихся> на иждивении $I$

Время вступления в Союз 1917

Секретарь Губотдела < подпись> 
Зав. орготделом $<$ подпuсb $>$

Дата выдачи билета <не заполнено>

Печать

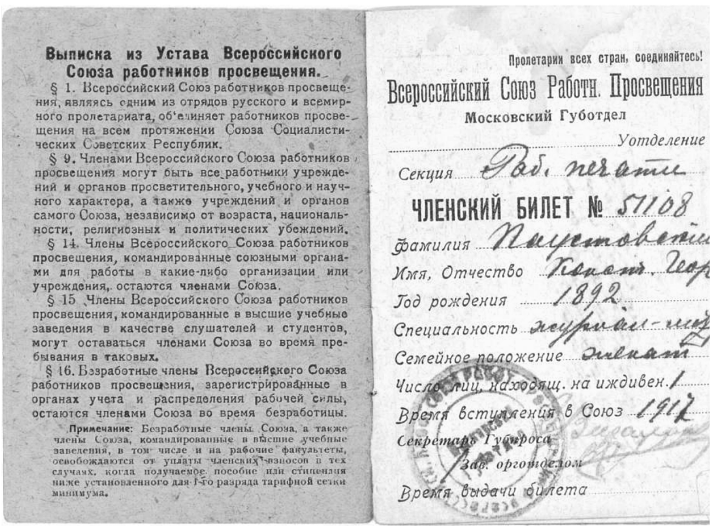

Членский билет Всероссийского союза работников просвещения на имя К.Г. Паустовского

Paustovsky's Membership ID of the All-Russian Union of Education Workers

\section{4. Удостоверение К.Г. Паустовского - специального военного корреспондента TACC. I94I}

Телеграфное агентство Советского Союза при Совнаркоме СССР

TACC

\section{УДОСТОВЕРЕНИЕ}

Предъявитель сего тов. Паустовский Константин Георгиевич является специальным военным корреспондентом ТАСС в Действующей Красной Армии.

Действительно до зІ декабря I94I 2.

Ответственный руководитель ТАСС $<$ подпись $>$ (Я. Хавинсон)

Москва, «27» июня I94I г. № 207

Печать

Личная подпись $<$ К.Паустовский>

Зав. отделом кадров $<$ подпись $>$

«27》 июня I94I г.

Печать 


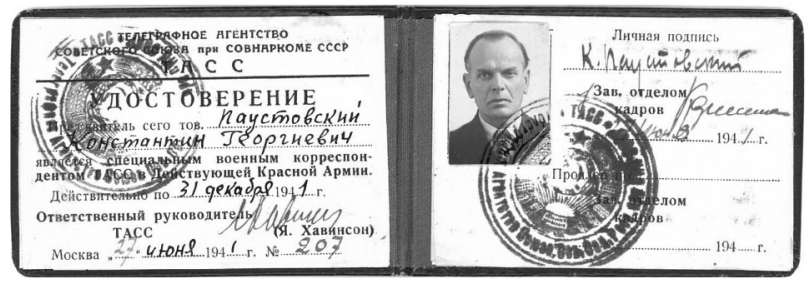

Удостоверение К.Г. Паустовского - специального военного корреспондента ТАСС. I94I

Paustovsky's ID as a special military TASS correspondent, I94I

\section{5. Дарственная надпись К.Г. Паустовского В.В. Навашиной.}

\section{Январь 1947.}

Валюшке - первый экземпляр книги, которую она уговорила меня написать.

Костя.

Январь, 47 г.

На книге:

Паустовский К. Далекие годы. Повесть о детстве и юности. Рис. Б. Дехтерева. М. - Л.: Детгиз, І946. 332 с., илл.

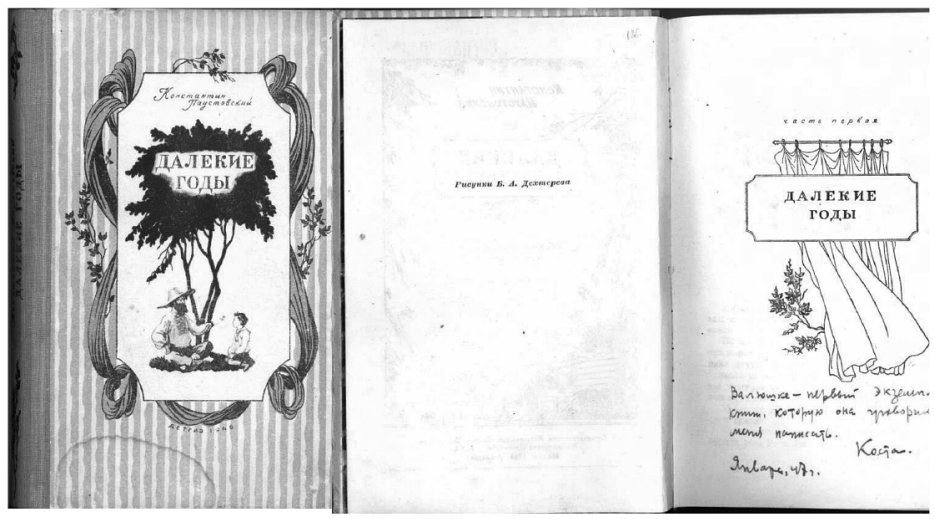

Дарственная надпись К.Г. Паустовского В.В. Навашиной. Январь 1947 Inscription dedicated to V.V. Navashina. January 1947 